Уваров Игорь Алексеевич

кандидат юридических наук, доцент, доцент кафедры криминалистики Ставропольского филиала

Краснодарского университета МВД России

\section{СОЛИДАРИЗАЦИЯ \\ ПЕНИТЕНЦИАРНОГО СООБЩЕСТВА КАК ОСОБЫЙ ВИД СОЦИАЛЬНО-КОММУНИКАТИВНЫХ СВЯЗЕЙ}

\begin{abstract}
Аннотация:
Изменение социально-экономических отношений в нашей стране существенно повлияло на интенсивность информационной коммуникации. Следствием этого стала серьезная трансформация социальных отношений. Изменения затронули и пенитенциарное сообщество, традиционно рассматриваемое как пример стабильности социально-коммуникативных связей. Такого рода процессы выступили фактором, изменивиим социальную структуру всего пенитенциарного социума. На этом фоне стали проявляться совершенно иные признаки объединения пенитенциарного сообщества, которые ранее рассматривались как неприемлемые с позиции неформальных отношений. В статье анализируются основные принципы солидаризации в пенитенциарном сообществе, обусловленные современным состоянием социально-коммуникационной сферы. В этой связи затрагивается и проблема самоидентификации представителей пенитенциарного сообщества. В завершение статьи дается оценка качественному состоянию солидаризации пенитенциарного сообщества на основе современных социально-коммуникативных связей.
\end{abstract}

Ключевые слова:

пенитенциарная солидарность, пенитенциарное сообщество, социально-коммуникативные связи социальная коммуникация.
Uvarov Igor Alekseyevich

PhD in Law, Associate Professor, Criminalistics Department, Stavropol branch of the Krasnodar University of the Ministry of Internal Affairs of the Russian Federation

\section{SOLIDARITY \\ OF THE PENITENTIARY COMMUNITY AS A SPECIAL TYPE OF SOCIAL AND COMMUNICATIVE RELATIONS}

Summary:

Changes in socio-economic relations in our country have significantly affected the intensity of information communication. This resulted in a serious transformation of social relations. The changes also affected such a specific social community as the penitentiary community, which is traditionally considered as an example of stability of social and communicative ties. Such processes were a factor that changed the social structure of the entire penitentiary society. Against this background, completely different signs of unification of the penitentiary community began to appear, which were previously considered unacceptable from the position of informal relations. The paper dwells upon the basic principles of solidarity in the penitentiary community, due to the current state of the social and communication sphere. In this regard, the problem of self-identification of representatives of the penitentiary community is analyzed. In conclusion, the assessment is given of the qualitative state of solidarity of the penitentiary community based on modern socio-communicative ties.

Keywords: penitentiary solidarity, penitentiary community, social and communicative relations, social communication.

Социальные процессы современности характеризуются высокой степенью динамичности, следствием чего является обострение дифференциации как между социальными образованиями, так и внутри них. Данный процесс связан с наблюдаемой в последние десятилетия изменчивостью социальных коммуникаций. Актуализация данной проблемы носит глобальный характер, вследствие чего возникают вопросы нормативного определения социально-коммуникативных связей. В частности, некоторые социальные образования не только оказывают влияние на характер коммуникативных связей в отдельных сегментах общественных отношений, но и предпринимают попытки выстраивать свои собственные. К ним относится и пенитенциарное сообщество, демонстрирующее специфическое воздействие на социальные коммуникации. Будучи встроенным в определенные общественные отношения, данное сообщество формируется на основе специфических принципов [1, с. 40-43].

Для людей, которые в отличие от осужденных, изолированных от общества, могут свободно устанавливать любые социально-коммуникативные связи, даже географическая удаленность не является препятствием для общения [2, с. 127]. Представители же пенитенциарного сообщества находятся в более сложном положении. Преодоление трудностей, обусловленных характером отбывания наказания, условно можно отнести к «естественным преградам», затрудняющим установление (осуществление) коммуникативных связей. Если есть «естественные» препятствия, должны быть и «искусственные». Интересным, на наш взгляд, является тот факт, что в современной науке распространена точка зрения, в соответствии с которой искусственные 
преграды сопряжены только с характером отбывания наказания [3, с. 129]. Рассматривается это как некий очевидный факт, связанный с изоляцией от общества. Можно предположить, что такие представления обусловлены отсутствием понимания реальных социально-коммуникативных отношений, существующих в пенитенциарном социуме. Даже в самых хорошо организованных условиях, обеспечивающих изоляцию осужденных от общества, как показывает практика, существуют специфические формы социальных коммуникаций, позволяющие «обходить» утвержденные правила. Именно поэтому мы можем называть их «естественными», т.е. связанными с условиями отбывания наказания.

Для понимания сущности подобных типов взаимодействия не нужно забывать, что социально-коммуникативные процессы - явление весьма динамичное. На протяжении своей длительной истории они подвергались существенным изменениям как по форме, так и по содержанию. Изначально пенитенциарная коммуникация носила исключительно локальный характер, обусловленный «закрытостью» и специфичностью пенитенциарного социума. Однако с развитием социальных отношений в «свободном обществе» неформальные связи в условиях мест лишения свободы претерпели определенного рода трансформацию. Ускорение социальных процессов привело к усложнению внутренней структуры коммуникативных отношений и в пенитенциарном социуме [4, с. 113].

Вышеназванные изменения в структуре общественных отношений «свободного общества» повлияли на интенсификацию взаимодействия между различными субъектами, участвующими в этих отношениях. Это стало причиной различных негативных процессов, влияющих на общепринятые представления о характере социальных коммуникаций. Следствием же явилось фрормирование социальных групп, выстраивающих своеобразную защиту от проникновения в них новых коммуникационных связей, воспринимаемых как деструктивные. В то же время подобного рода группы в «большом обществе» также игнорируются, считаются маргинальными, так как субъекты социальных отношений не готовы освоить правила новых коммуникативных отношений. Таким образом, интеграционные процессы в современном обществе одной частью населения воспринимаются как негативные, а другой - как позитивные. Суть противоречия лежит в плоскости определения природы этих процессов - естественной или противоестественной. Закономерным результатом становится осложнение ситуации качественной оценки социальных коммуникаций. Учитывая полярность фиксируемых отношений субъектов общественного взаимодействия к новым социальным связям, можно говорить о процессе солидаризации индивидов на этой основе, который субъективно воспринимается ими как негативный или позитивный [5, с. 267-270].

Здесь нужно отметить, насколько то или иное социальное образование способно выразить степень солидаризационных процессов в отстаивании ценностной ориентации своих членов. Интересную мысль в этой связи высказал В.В. Плотников: «Индивидуальная субъективность экстраполирует свое мировоззрение на надындивидуальную субъективность некоторой социальной общности и находит в ней достаточное отражение» [6, с. 159-161]. Исследователь отмечает очень важную, на наш взгляд, закономерность, которая свидетельствует о том, что чем больше развито у человека индивидуальное мировоззрение, тем более целостной будет и его система ценностей. Более того, различные аксиологические ориентации и составляют в совокупности мировоззренческую систему социальных образований [7, с. 160], что можно применить и к пенитенциарному сообществу.

Необходимо обратить внимание также и характерную особенность, которая присуща исключительно условиям мест лишения свободы. Если в «свободном» обществе система ценностей его членов характеризуется высокой степенью динамичности, что определяет сложность формирования общей мировоззренческой конструкции, то в условиях изоляции от общества такое положение дел невозможно. Иерархичность системообразующих принципов, обусловливающих общие мировоззренческие подходы, остается неизменной на протяжении десятилетий. В условиях лишения свободы качественный состав осуждённых изменяется (ратируется) за счет приходящих из «свободного» общества.

Периодическая сменяемость состава осужденных в местах лишения свободы ведет к увеличению темпов информационного обмена в пенитенциарном социуме. Безусловно, от качественного состава лиц, отбывающих наказание в конкретном виде режима содержания, существенно зависит и характер информационного обмена между ними. Чем менее строгий режим содержания исправительного учреждения, тем четче проявляется процесс отбора субъектов коммуникации с «дроблением» пенитенциарного социума на многочисленные «тематические» группы. Но такого рода нестабильность состава осужденных характерна для лиц, отбывающих наказание впервые. Отсюда и интенсификация процесса социальной коммуникации, обусловленная насыщенностью информационного пространства новыми мировоззренческими установками, вступающими в противоречия с традиционными и устоявшимися ценностными приоритетами в 
местах лишения свободы. Основной проблемой здесь может быть то, что вновь прибывшие осуждённые (особенно те, к которым не применялось заключение под стражу) склонны к идеализации нефрормальных отношений, существующих в местах лишения свободы. Коммуникативные связи, формирующиеся в пенитенциарном социуме, напротив, менее подвержены принятию тех мировоззренческих установок, которые считаются «приемлемыми» для «свободного» общества.

Здесь важно отметить, что основными носителями эклектичного мировоззрения в условиях изоляции от общества являются представители именно пенитенциарного сообщества. Они легко улавливают противоречивость социальных представлений в сознании вновь прибывшего осужденного о коммуникативных отношениях «свободного» и «закрытого» общества. Это позволяет им успешно манипулировать поверхностными представлениями новичков о системе неформальных отношений в условиях лишения свободы. Причина такого положения дел кроется в том, что мировоззрение вновь прибывших основано на разнообразных социальных представлениях. Именно поэтому они зачастую становятся мишенью для разного рода манипуляций.

Мы считаем, что в этом проявляется дуальность рассматриваемого процесса. С одной стороны, его основу составляют представители пенитенциарного сообщества, солидаризирующиеся на четко определенных неформальных принципах консолидации (распределение ролей, общность социальных признаков и т.п.). А с другой - имеет место перманентное осуществление солидаризационных процессов всего пенитенциарного социума. Поэтому до тех пор, пока речь идет о непринципиальных социальных признаках (условно их можно назвать «общесоциальными», т.е. не влияющими на целостность пенитенциарного социума), дуальность не нарушается. Эти процессы развиваются параллельно. Но если возникают прецеденты актуализации групповой идентичности носителей определенного социального признака, противоречащего сугубо пенитенциарным установкам, последние актуализируются, чтобы не допустить возникновения различий между остальными членами пенитенциарного социума. Так, например, могут возникать конфрликты на базе различий в вероисповедании, национальности или территориальной принадлежности осужденных. В то же время нужно сказать, что конфрликт на этой почве может возникнуть, если указанные характеристики выступают в качестве детерминирующих оснований для консолидации. В таких случаях представители пенитенциарного сообщества проявляют коллективное неприятие индивида, обладающего отличительным социальным признаком, что становится демонстрацией десолидаризирующего настроения во всем пенитенциарном социуме [8, с. 43-51].

Существует мнение, согласно которому в условиях изоляции от общества проявляется некая «механистическая» солидаризация осужденных [9, с. 75-79]. Такого рода консолидация при ограничении свободных коммуникативных контактов не способствует формированию пенитенциарного социума как такового. Например, с формальной точки зрения, отряд осужденных можно рассматривать как некую социальную общность внутри исправительного учреждения, однако каких-либо признаков «механистической» солидарности мы здесь найти не сможем. Вероятнее всего, исследователи, придерживающиеся такой точки зрения, исходят из того, что в качестве консолидирующего основания берется некое качество, присущее всей общности осужденных [10, с. 102-111].

Таким образом, преодоление деструктивных форм солидарности в пенитенциарном сообществе существенно отличается от аналогичных процессов в «свободном» обществе по целому ряду признаков. К наиболее значимым характеристикам, на наш взгляд, следует отнести то, как эта коммуникативная общность соотносится с иными формами включенности в нее любого социального субъекта; посредством каких социально-коммуникативных связей такая общность может рассматриваться как единое целое и какова ценностная иерархия личности в этой социальной системе. Говоря о таких процессах, происходящих в пенитенциарном социуме, необходимо констатировать специфическую природу сложившихся здесь социально-коммуникативных отношений. Качественная оценка конструктивности или деструктивности конкретного типа социальной солидарности пенитенциарного сообщества детерминируется его соответствием тому месту, которое оно занимает в системе социального взаимодействия субъектов пенитенциарного социума.

\section{Ссылки}

1. Уваров И.А. Идеология пенитенциарного сообщества в системе формирования общественного сознания осужденных // Вестник института: преступление, наказание, исправление. 2012. № 2 (18). С. 40-43.

2. Пикин И.В., Пикина Т.В. Ограничение правового статуса при реализации государственного принуждения, связанного с изоляцией от общества // Борьба с пенитенциарной преступностью: опыт, проблемы, перспективы. Владимир, 2013. С. $127-132$.

3. Там же. С. 129.

4. Пенитенциарная криминология: учебник / под ред. Ю.М. Антоняна, А.Я. Гришко, А.П. Фильченко. Рязань, 2009. 566 с.

5. Толстых А.C. Пенитенциарные учреждения в процессах социализации // Обеспечение прав человека в условиях современного государства. Владимир, 2010. С. 267-270. 
6. Плотников В.В. Надындивидуальный субъект, как категория социально-гуманитарного познания // Актуальные вопросы социогуманитарного знания: история и современность. Краснодар, 2018. С. 159-161.

7. Там же. С. 160

8. Уваров И.А. Пенитенциарное сообщество в системе факторов, противодействующих нормальной деятельности уголовно-исполнительной системы // Актуальные проблемы современного российского права. Невинномысск, 2007. C. 43-51.

9. Исаева О.П. Социальная самоорганизация осужденных в местах лишения свободы России как фактор, способствующий возникновению феномена «тюремная община» // Проблемы ювенальной юстиции и системы исполнения наказаний. Самара, 2011. С. 75-79.

10. Голубев В.П., Хохряков Г.Ф. Ценностные ориентации и их влияние на противоправное поведение осужденных // Социально-психологические и правовые проблемы профилактики правонарушений в исправительно-трудовых учреждениях. Рязань, 1982. С. 102-111.

Редактор: Ситникова Ольга Валериевна Переводчик: Бирюкова Полина Сергеевна 